\title{
Population and development: a festschrift in honour of Professor K. A. P. Siddhisena, Department of Demography, University of Colombo edited by Lakshman Dissanayaka and Swarna Ukwatte (Department of Demography, University of Colombo: Colombo, 2015, Rs. 2000/-)
}

\author{
Reviewed by Chandra Gunawardena* \\ Emeritus Professor, The Open University of Sri Lanka, Nawala, Sri Lanka.
}

The Felicitation Volume in honour of Prof. Siddhisena titled Population and Development contains 16 articles, of which the first provides a biographical sketch of Emeritus Professor Siddhisena. In this biographical sketch, Dr. Sunetra Perera places on record the lifetime work of Prof. Siddhisena, which would enable junior academics and students to recognise his immense contribution to the discipline of Demography as an academic as well as an academic administrator and motivate them to emulate him for their own career development. It is followed by a list of Prof. Siddhisena's publications in international and national peer-reviewed journals and research papers in conferences. The breadth of his academic interests span demography, poverty, livelihood support, labour force and manpower, alcoholism, trafficking of women and children, urbanisation and migration.

It is significant that four of the chapters are contributions from eminent foreign academics with international repute: Graeme Hugo, former Australian Professorial Fellow, Professor of Geography and Director of the Australian Population and Migration Centre, University of Adeaide; Deborah S. Degraff, Professor, Department of Economics, Bowdoin College, Brunswick, USA; Rebecca Wong, Professor, University of Texas Medical Branch, Sealy Center on Aging, Galveston, Texas, USA; David Lucas and Barbara Edgar of the Australian Demographic and Social Research Institute, Australian National University and Gouranga Lal Dasvarma, Adjunct Associate Professor in Population Studies, School of Environment, Flinders University, Adelaide.

Of the sixteen chapters, three focus on the elderly and aging, two on Sri Lankans in Australia, two on economic development, two on migration, and one each on under five mortality, differential educational attainment, morbidity and mortality in Sri Lanka, global poverty, development and conservation, cognitive/ mental mapping for research and population growth and lawlessness in colonial Sri Lanka. As such it is a truly comprehensive volume spanning several major areas of concern.

Lakshman Dissanayake and Swarna Ukwatte in the Introduction to the volume, touch on each of the sixteen chapters. As my responsibility is to review the volume, I will also attempt to focus on each chapter. I will try to review the chapters in relation to the themes they focus on rather than sequentially.

Graeme Hugo has profiled comprehensively the demographic dynamics, characteristics and distribution of the Australian Sri Lankan community. Pointing out that the Australian Sri Lankan community is the $6^{\text {th }}$ largest in the diaspora, he describes the growth of the community and its ethnic composition. Among the important characteristics Hugo points out are that the fertility rate of Sri Lankans is lower as a result of their higher levels of education and that the Sri Lankan born-women had lower mortality rates than the Australian born. Analysing the age-wise distribution of the Sri Lankans, he points out the under-representation of those between 0-24 and 65+ and that more than 40 per cent of the Sri Lankan community had university degrees or higher qualifications and are more concentrated in the more skilled occupational categories and professional occupations, thus leading to a significant loss of human capital to Sri Lanka. 
David Lucas and Barbara Edgar have also contributed a chapter on Sri Lankans in Australia. They trace the number of Sri Lankans born in Australia from 1901 to 2011, paying attention to the Burghers who predominantly migrated from 1950 s to 1970 s and how after the repeal of the White Australia policy and due to political unrest after 1970s in Sri Lanka, the number of migrants had increased. Sixty per cent of the original Sri Lankan migrants lived in Victoria and even in 2011, $51 \%$ were living there. They compared the 'ancestry' as given by Sri Lankan migrants by ethnic and religious backgrounds. They also point out as Hugo did that Sri Lankan migrants were considered to be highly educated, proficient in English and over-represented in the professions.

Three of the chapters focus on economic issues. Prof. A. D. V. De S. Indraratne, Emeritus Professor of Economics, University of Colombo, discusses "The knowledge economy and economic growth and development: a nexus". Indraratne defines knowledge economy that knowledge economy, creates, disseminates, inputs or uses knowledge to promote growth and development. He correctly stresses that knowledge economy should not be interpreted to signify only information society or high technology or ICT but should encompass appropriate knowledge pertaining to all systems and be utilised to promote inclusive growth and thereby increase the welfare and quality of life of the people. He refers to the four main pillars of the knowledge economy, - the environment, ICT, human resource development or investment in human capital and innovation. He points out that in Sri Lanka, a marked transformation of the economy had taken place in the last six decades. Focusing on future prospects Indraratne emphasises that achieving the goal of becoming a middle income country will depend on Sri Lanka's ability to emerge as a knowledge economy and the speed at which it can be timed into a commercial opportunity. He identifies inadequacy of budgetary resources, low ICT penetration and institution of R \&D especially for public sector research and technology as issues.

Lakshman Yapa, Professor of Geography, Pennsylvania State University, USA, has chosen "Why economic development will not eradicate poverty" as the title of his short chapter. Analysing costs borne by US on food, health and housing, Yapa argues that the kind of economic development advocated by the World Bank has not and will neither eradicate poverty nor provide good nutrition, good health and affordable housing for all people. Similarly, he points out that economic growth achieved by China has resulted in severe environmental degradation and by India has not resolved the issues of slum populations. He argues that poverty eradication must be located in civil society. Under basic needs economy, Yapa provides some examples from Milwaukee to indicate the success of organisations that carry on urban farming using little capital and from Cuba where extension services to help bio-intensive urban farming were provided.

Ruwan Jayatilleke, Visiting Lecturer, University of Colombo, has contributed a comprehensive chapter on "Poverty concepts, trends in global poverty and Sri Lanka". He emphasises that the concept of poverty is complex and 'slippery'. Definitions range from narrow definitions in terms of income or consumption to broader definitions, in terms of human development, social exclusion, lack of capability in functioning, economic and social vulnerability, livelihood and sustainability, inability to achieve basic needs and relative deprivation. Referring to the pyramid of poverty concepts, he points out that the top of the pyramid represents the narrowest definition while the bottom represents the broadest definition.

In a subsequent section, Jayatilleke differentiates between objective and subjective perspectives, and chronic and transient poverty. He discusses measurements of poverty such as poverty headcount index, the depth of poverty index, the poverty severity of poverty index, the Foster-Greer-Thobecke poverty index, the human poverty index and the Multi-Dimensional Poverty Index in detail. Finally, the Multi-Dimensional Poverty Index introduced by UNDP Human Development Reports is dealt with.

Chapter Four by DeGraff and Wong, presents an "Estimation of models of outcomes among the elderly". The authors point out that in order to better understand the dynamics underlying the observed conditions of the elderly, early-life influences need to be considered. They argue that statistical models that consider only current or recent characteristics and conditions may yield misleading results. They admit, however, that inclusion of these variables is likely to introduce bias. They have identified three aggregate census variables, that shape the context for early-life education and marriage decisions of the elderly cohorts: an age-based male to female sex ratio, a sex and age-specific percentage married and sexspecific literacy rate. They propose a novel approach of using historical context data derived from censuses to construct aggregate measures of historical, social, demographic and economic conditions that are relevant to the early-life behaviours.

Dasvarma discusses the "Challenges of population aging comparing Australia and India". Dasvarma explains 
that changes in the age-structure of the population leading to population aging are the consequences of demographic changes over a long period of time. He points out that the two main determinants of population aging is decline in fertility and mortality. He points out that in India fertility has always been higher than in Australia. Both countries have recorded improvements in longevity and females have maintained an advantage over males. The author presents evidence in the form of data tables and figures on population pyramids to substantiate the changes in the age structure of the respective populations. Dasvarma points out the implications of population aging in India that due to lack of access or not being aware of the provisions and social security benefits the aged have to depend on support from families and personal savings and that the concept of 'healthy aging' is yet to gain acceptance in India. On the other hand, Dasvarma points out that a large number of programmes provide support and services for the elderly in Australia.

Manori Kaluthanthri Weeratunga, Lecturer, Department of Demography, University of Colombo, discusses a related issue - the aging process and its results in Sri Lanka. She explores the process and dynamics of aging through time in Sri Lanka. Defining aging as the increase in the relative proportion of the elderly in the population, she notes the onset of aging in Sri Lanka is considered as 60 years. Substantive fertility reduction and improvements in life expectancy during the past 50 years have led to the rise of the aged population. Drawing on census data and previous analyses of senior demographers, she shows that South Asia would have the $2^{\text {nd }}$ highest projected increase of the elderly for 20202050, with Sri Lanka experiencing a greater spread of aging in the first half of the century and that the speed of aging in Sri Lanka will be greater than in all other regions of the world for 2010-2040. Weeratunga has identified fertility decline, advancements in medical science and increasing access to quality health care as the causes leading to improvements in life expectancy. As pointed out by the previous authors, she explains that the changing balance among age groups would result in a change from youth dependency to older dependency and that the median has shifted from 21 years in 1981 to 32 in 2012. The subsequent sections of the chapter focus on the feminisation of aging and marital status of the elderly. She emphasises that these changes would have a significant impact on the role of the family.

Lakshman Dissanayake, Senior Professor of Demography, University of Colombo, has contributed a chapter on "Recent trends of morbidity and mortality in Sri Lanka". He has utilised a diversity of data sources to position Sri Lanka's morbidity and mortality trends within the global perspective. He points out that during the past 100 years, a decline of mortality has occurred at all ages for both sexes. Percentage decreases in rates of mortality have been highest for infants and children and the rapidity of improvement has been greater for females, especially after 1960s. Even though prevalence of infections and respiratory diseases show a marked decline during the past two decades, heart diseases, cancer, stroke and diabetes have become widely prevalent. Female life expectancy has increased compared to that of males as men are more vulnerable to degenerative and man-made causes. Dissanayake also points out that though people will survive longer they will spend the extended years in a state of sickness and disability. The author also notes that while Sri Lanka has moved away from epidemics and famines, there is an emergence of new diseases such as dengue, Japanese encephalitis, chikungunya and HIV/AIDS/STI infections. He concludes that declining morbidity and mortality will produce a healthier labour force in Sri Lanka.

Gaminiratne Wijesekere, Visiting Fellow, Australian Social and Demographic Research Institute, Australian National University, has contributed a chapter on "Sri Lanka's under-five mortality estimation for measuring progress on Millennium Development Goals: a comment and suggestions for improvement". The paper comments on the method used for compiling under-five Infant Mortality Rate (IMR) for Sri Lanka and suggests an alternative method for estimating under-five IMR. Under five mortality rates could be calculated using data from household surveys conducted on representative samples but the quality of data can be affected by sampling and non-sampling errors. In addition there can be reporting errors on age of children and dates of the deceased children. The author points out that while UNICEF uses the summary birth approach that too can result in overstating child mortality. Commenting that the coverage of the Vital Registration System in Sri Lanka has improved over the years, Wijesekere points out that still there can be inaccuracies. He states that MDG Guidelines could yield reasonable results but only if the number of live births does not change substantially from year to year. Wijesekere proposes the cohort method as an alternative, where the mortality experience of a cohort of babies born in a given calendar year is assessed as this cohort passes through infancy and childhood, subject to age-specific mortality rates applicable to those ages. He points out that the advantage of using the cohort method is that it assesses the probability of a child born alive in a particular year dying at different ages following birth when he or she passes through infancy and early childhood subject to the age-specific mortality pattern prevailing at those ages. The strength of the paper is the author proceeding to critique the method being used at present to posit an alternative method. 
Chapter 15 on "Neglected issues around gender and migration in Sri Lanka: a profile of the marital life of left behind women and its demographic implications" is a contribution by Kumudika Boyagoda, Lecturer, Department of Demography, University of Colombo. The author points out that there has been considerable discussion on the consequences of female migration on the family left behind, studies on male migration from Sri Lanka has been neglected. She points out that as a result of male migration, Female-Headed Households have increased and the paper explores the characteristics and socio-economic issues related to 42 Female-Headed Households. Data analysed qualitatively has been presented in the article. The age at marriage of the women in the sample ranged from 16 to 29 years and $43 \%$ of the women had been in their 30s when the spouse migrated. For nearly $1 / 3$ of the women, life with a physically present spouse had been quite short. The issues had impacted on fertility, use/non-use of contraceptives, effects on sexual and general health, marital stability and changes in household composition. The paper's significance lies in the fact that it had focused on a scantily researched issue and that, despite the small sample, rich narrative excerpts had been included. If the sources referred to as cited works had been included in the references it would have been more useful to the reader.

Swarna Ukwatte, Senior Lecturer, Department of Demography, University of Colombo has written on "Female migration for overseas employment: social costs and benefits". She commences the chapter referring to the changes in the global labour markets that have increased opportunities for both men and women to migrate internationally for employment in large numbers. She explains that benefits include economic remittances but also social remittances such as changes in consumption patterns, values, attitudes and modes of bringing up children, clothing and even food preferences. She explains that female migration can have a positive influence on gender norms in the country of origin, enhance autonomy and power of women and even change gender roles of family members. At the same time, separation of the family from men can have a negative influence on families. She also highlights that women become the principal breadwinners during the period they work abroad, but as the period of employment is short, the husbands are regarded as the principal wage earners. Among the other benefits identified are acquisition of new skills such as speaking a new language, proper management of household duties, use of electrical appliances and capability to work outside the home as well as personal development. She also identifies negative effects of female migration such as husbands' alcoholism, drug addiction, gambling and misbehavior and ill-health of children. Ukwatte concludes that the economic benefits to some extent are offset by the adverse effects of migration especially for the children who are affected by the absence of the mother.

Dayalal Abeysekere, Formerly Associate Professor, Department of Sociology, University of Sri Jayawardenepura, has contributed an article on "Persistence of substantial differential educational attainment among ethno-religious communities in Sri Lanka after a century of free education: a quasi-cohort analysis". The study analyses data from the 2001 census. The age variable used was those who were born between $1^{\text {st }}$ February 1975 and $31^{\text {st }}$ January 1976, who would have been between 25 to 26 years of age at the 2001 Census enumeration. Due to the non-inclusion of eight districts in the North and East, there was an under-estimation. A simplified index of the entirety of the percentage distribution in addition to perusing comparative median level of education across Ethno-Religious Grouping (ERG) was used. Abeysekere points out that with the passage of time and introduction of free education and political independence, the females have managed to catch up with the males and eventually surpass the latter within about three decades. He points out that on average, half of the female born between $1^{\text {st }}$ February 1975 and $31^{\text {st }}$ January 1976 have passed the first public examination held in Sri Lanka while half of their male counterparts have not done so. Only Sri Lankan Moor-Muslim and Indian Tamil community had males surpassing females. In the case of Sinhalese, Sri Lankan Tamil and Indian Tamils, Roman Catholic and other Christians, both males and females had improved their educational attainment. Author expresses concern regarding the under-achievement of both male and female Indian Tamil population. He concludes that only five out of 22 ERGs surveyed had demonstrated improved educational performance in response to the public investment policies sponsored by successive governments.

The second chapter, "A world in flux: the economic transition, population growth and lawlessness in the nineteenth century Sri Lanka" is a contribution of S. A. Meegama, the former Director of United Nations Statistical Institute for Asia and the Pacific, Tokyo, Japan. In this comprehensive chapter, Meegama traces the lawlessness that spread in the maritime provinces, due to the people being compelled to cultivate export crops and the neglect of food crop cultivation, by the colonial rulers to increase criminal activity, which included gang robberies, kidnapping of children for sale for slavery. Meegama, with evidence points out that measures such as the abolition of Rajakariya, opening up of coffee plantations, peasantry being subjected to heavy taxes leading to a loss of means of subsistence and the construction of roads and railways for the development of plantation industry had finally led to 
the gradual destabilisation of the village society. The strength of this contribution is that the author draws on relevant documentation to explain how the money economy contributed to an increase of crime, with criminals thriving due to an absence of a well-designed law enforcement apparatus. Descriptions of the highway robberies, the activities of the businessmen who were supposed to assist the police but who worked with the gang robbers are interestingly presented.

Meegama also comments on the influence of the caste and the influence of ethnic and religious issues on conflict. He also analyses the influence of population growth on property relations, on lawlessness and crime in this period. He shows that sub-division of holdings, had led to family disharmony and violence. In addition, dearth of employment, increasing gambling and unsatisfactory succession to property also led to lawlessness.

"The central region of Sri Lanka development with a focus on conservation" is the title of article of Prof. W. N. Wilson, Professor in Geography, University of Colombo. The objective of the study is given as the identification of the resource base and development of potential of the Central Province highlighting the main development constraints. He identifies the economic, social, environmental and political benefits that can be gained by concentrating on development within the region. Accordingly, he discusses the geographical, socioeconomic (population, education, medical facilities, transportation and land use) profiles and subsequently the development potential and constraints in the region. The author focuses on the development constraints such as soil erosion, landslides, waste generation and disposal.
The chapter concludes with a discussion of legislation, policies and institutional frameworks pertaining to the above issues. The chapter could have been enriched through an identification of strategies to resolve the identified constraints.

Prof. Yoga Rasanayagam, Emeritus Professor, University of Colombo has contributed a chapter on the novel technique of Cognitive/Mental Mapping for Research and training in the Social Sciences. After introducing the concept of "mental maps" Rasanayagam discusses the advantages of mental maps as tools of research. She points out, with illustrations and a detailed discussion drawing on relevant studies that the method is valuable especially in involving relevant stakeholder groups in creating a research project. Special emphasis is given to mental maps and geography, mental maps and locational decisions and mental maps and planning as well as its limitations. The chapter could have benefitted from a discussion of the Sri Lankan context, whether mental maps have been used and if so, the extent of success and if not, why.

I consider it as my privilege to be requested to review a volume which contains chapters on diverse topics and issues, ranging from economic development, elderly and aging, morbidity and mortality, poverty, migration, conservation, mental mapping and lawlessness. Almost all the chapters are detailed and comprehensive, touching on all the aspects that deserve exploration. As such the volume does justice to the intention of honouring a senior university professor whose excellent contribution to the academic disciplines is undoubtedly at the highest level not merely nationally but also internationally. 